\title{
Evaluation of air-displacement plethysmography for body composition assessment in preterm infants
}

\author{
Paola Roggero', Maria L. Giannì', Orsola Amato', Pasqua Piemontese', Daniela Morniroli', William W. Wong² and Fabio Mosca'
}

BACKGROUND: Adiposity may contribute to the future risk of disease. The aim of this study was to evaluate the accuracy and reliability of an air-displacement plethysmography (ADP) system to estimate percentage fat mass (\%FM) in preterm infants and to evaluate interdevice reliability in infants.

METHODS: A total of 70 preterm and 9 full-term infants were assessed. The accuracy of ADP measurements was assessed by determining reference \%FM values using $\mathrm{H}_{2}{ }^{18} \mathrm{O}$ dilution measurement.

RESULTS: Mean \%FM by ADP was $5.67 \pm 1.84$ and mean \%FM by $\mathrm{H}_{2}{ }^{18} \mathrm{O}$ dilution was $5.99 \pm 2.56$. Regression analysis showed that \%FM by ADP was associated with \% FM by $\mathrm{H}_{2}{ }^{18} \mathrm{O}$ dilution $\left(R^{2}=0.63\right.$, SE of estimate (SEE) $\left.=1.65, P=0.006\right)$. Bland-Altman analysis showed no bias $(r=-0.48, P=0.16)$ and $95 \%$ limits of agreement were -3.40 to $2.76 \% \mathrm{FM}$. There was no difference in mean interdevice reliability \%FM values (8.97 vs. $8.55 \%$ FM) between ADP 1 and 2. Regression analysis indicated a low SEE (1.14\% FM) and high $R^{2}(0.91) ; 95 \%$ limits of agreement were -1.87 to $2.71 \% \mathrm{FM}$. The regression line did not differ significantly from the line of identity.

CONCLUSION: ADP is a noninvasive, reliable, and accurate technique to measure preterm infants' body composition in both research and clinical settings.

$\mathbf{T}$ here has been an increasing focus on nutrition and its impact on the quality of growth in preterm infants (1-3). Indeed, body composition, in terms of fat mass (FM), may contribute to the future risk of disease (4).

Until recently, body composition assessment techniques were feasible by using skinfold calipers, dual-energy x-ray absorptiometry, bio-impedance analyzers, and stable isotope dilution, where total-body water is measured. Fat-free mass (FFM) and, consequently, FM are calculated by knowing the hydration in FFM and multicomponent models where bone mineral, protein, and water in the body are directly measured. Reference techniques such as deuterium dilution and fourcompartment models, while accurate, are also more cumbersome and resource intensive $(5,6)$.

In 2004, an air-displacement plethysmography (ADP) system for infants (PEA POD, COSMED USA, Concord, CA) was introduced and has been validated in a systematic manner beginning with known volume phantoms, moving on to bovine tissue, and finally to human subjects, where the system was validated against the deuterium dilution method and a multicompartment reference model. The system has proven to be accurate in mass and volume measurement of inanimate objects as small as $1 \mathrm{~kg}$ and in full-term newborn infants weighing $>2.7 \mathrm{~kg}(7-11)$.

With increasing focus on nutrition for preterm infants, it is important to have an accurate, precise, and noninvasive body composition assessment technology that is suitable for use even in these vulnerable infants in the clinical environment $(12,13)$. Moreover, the availability of a body composition assessment technology that has a good interdevice reliability is crucial for determining overall validity and has practical implications for multicenter studies including intersite testing and acceptance as a reference method for assessing body composition.

Therefore, the goal of this study was to evaluate the accuracy of an infant ADP system in reference to a total-body water model for use in preterm infants. In addition, this study aimed to evaluate the precision and the interdevice reliability of the ADP for percentage FM (\%FM) estimates in premature infants.

\section{RESULTS}

The anthropometric characteristics of the population that participated in the study are given in Table 1.

With regard to the precision section of the study, the results are presented in Table 2. The \%FM obtained in ADP Test 1 was not significantly different from that of ADP Test 2 (mean difference: $0.15 \% \mathrm{FM} ; P=0.34$ ), with mean within-subject SD of 1.1 $\% \mathrm{FM}$. The results of the linear regression analysis between the two ADP tests are presented in Figure 1a. Results confirmed the reproducibility of the ADP tests, with slope and intercept values not different from 1 and 0 , respectively (SE of estimate $\left.(\mathrm{SEE})=2.11 \% \mathrm{FM} ; R^{2}=0.85 ; P<0.001\right)$. The results of the Bland-Altman analysis for repeated \%FM tests are presented in Figure 1b. Good agreement was observed between the tests, with a mean bias of $0.15 \% \mathrm{FM}$; the $95 \%$ limits of agreement were at -2.05 and $2.36 \% \mathrm{FM}$.

\footnotetext{
'Department of Maternal and Pediatric Sciences, Fondazione IRCCS “Ca'Granda" Ospedale Maggiore Policlinico, University of Milan, Milan, Italy; ${ }^{2}$ United States Department of Agriculture, Agricultural Research Service Children's Nutrition Research Center, Baylor College of Medicine, Houston, Texas. Correspondence: Paola Roggero (paola.roggero@unimi.it) 
The results from the accuracy portion of the study for the measured parameters (total body water (TBW) and TBW\%) are presented in Table 2, along with the calculated values of FFM obtained with the $\mathrm{H}_{2}{ }^{18} \mathrm{O}$ dilution measurement. The ADP estimates for $\% \mathrm{FM}$ were not significantly different from the values obtained with the $\mathrm{H}_{2}{ }^{18} \mathrm{O}$ dilution measurement

Table 1. Anthropometric characteristics of the participants

\begin{tabular}{lccc}
\hline Number & $\begin{array}{c}\text { Precision } \\
(n=57 \text { PTs })\end{array}$ & $\begin{array}{c}\text { Accuracy } \\
(n=10 \text { PTs })\end{array}$ & $\begin{array}{c}\text { Interdevice } \\
\text { reliability }(n=9 \\
\text { FTs; } n=3 \text { PTs })\end{array}$ \\
\hline Sex (M/F) & $28 / 29$ & $6 / 4$ & $6 / 6$ \\
Age (d) & $32 \pm 32$ & $15 \pm 9$ & $6 \pm 0.5$ \\
Body mass (kg) & $1.89 \pm 0.59$ & $1.83 \pm 0.21$ & $2.9 \pm 0.8$ \\
$\begin{array}{l}\text { Gestational age at } \\
\text { assessment (wk) }\end{array}$ & $30.92 \pm 2.02$ & $32.50 \pm 1.95$ & $38.2 \pm 2.2$ \\
\hline
\end{tabular}

Data are expressed as mean \pm SD.

$\mathrm{FT}$, full-term infant; PT, preterm infant.

Table 2. Body composition measurements of preterm infants

\begin{tabular}{|c|c|}
\hline & Value \\
\hline \multicolumn{2}{|l|}{ Precision } \\
\hline Weight (kg) & $2.22 \pm 0.22$ \\
\hline$\% \mathrm{FM}_{\text {ADP Test } 1}$ & $9.24 \pm 5.57$ \\
\hline$\% \mathrm{FM}_{\text {ADP Test2 }}$ & $9.08 \pm 5.63$ \\
\hline \multicolumn{2}{|l|}{ Accuracy } \\
\hline Weight (kg) & $1.831 \pm 0.21$ \\
\hline TBW (kg) & $1.50 \pm 0.19$ \\
\hline Percentage TBW (\%) & $82.18 \pm 2.17$ \\
\hline $\mathrm{FFM}, \mathrm{H}_{2}{ }^{18} \mathrm{O}$ dilution & $1.71 \pm 0.18$ \\
\hline$\% \mathrm{FM}, \mathrm{H}_{2}{ }^{18} \mathrm{O}$ dilution & $5.99 \pm 2.56$ \\
\hline$\% \mathrm{FM}_{\text {ADP }}$ & $5.67 \pm 1.84^{*}$ \\
\hline
\end{tabular}

Data are expressed as mean \pm SD.

ADP, air-displacement plethysmography; FFM, fat-free mass; FM, fat mass; TBW, totalbody water; TBW\%, percentage of total-body water.

${ }^{*} P=0.53 \% \mathrm{FM}$ ADP vs. $\% \mathrm{FM} \mathrm{H}_{2}{ }^{18} \mathrm{O}$ dilution. (mean difference: $0.32 \pm 1.57 \% \mathrm{FM} ; P=0.53$ ). The BlandAltman analysis for \%FM obtained with the ADP system and $\mathrm{H}_{2}{ }^{18} \mathrm{O}$ dilution measurement is presented in Figure 2a. The differences between the values obtained with the ADP system and the $\mathrm{H}_{2}{ }^{18} \mathrm{O}$ dilution measurement were not a function of the mean values for the two methods $(P=0.16)$, indicating no systematic bias as body fatness increased. The $95 \%$ limits of agreement were at -3.4 and $2.76 \% \mathrm{FM}$. Linear regression for \%FM values obtained with the two methods is presented in Figure $\mathbf{2} \mathbf{b}$. The slope and intercept values were 1.1 (95\% confidence interval: $0.41,1.79)$ and $-0.272(95 \%$ confidence interval: $-4.37,3.82$ ), and were not significantly different from 1 and 0 , respectively $\left(\mathrm{SEE}=1.65 ; R^{2}=0.62\right.$; $\% \mathrm{FM} ; P=0.006$ ).

With regard to the interdevice reliability section of the study, the physical characteristics of the study subjects and the estimates of \%FM and their behaviors during the test are presented in Table 3.

Almost all infants were calm or presented little movement. Although three infants cried for a short period during the volume measurement, this behavior did not negatively affect the results.

Percentage of FM estimates by ADP 1 and 2 were highly correlated $(r>0.96, P<0.001)$. There was no significant difference in mean \%FM estimates ( 8.97 vs. $8.55 \% \mathrm{FM}$ ) between ADP 1 and ADP 2.

Linear regression and Bland-Altman analyses of \%FM estimates obtained from ADP 1 and ADP 2 are presented in Figure 3. The regression line did not differ significantly from the line of identity $(y=x)$, and the regression equation indicated a low SEE (1.14 \% FM) and a high $R^{2}(0.91)$. Individual variations in \%FM between the two units were within a relatively narrow range $(95 \%$ limits of agreement $=$ -1.87 and $2.71 \% \mathrm{FM}$ ). Further, there was no trend in individual differences between \%FM estimates by ADP 1 and ADP 2 as $\% \mathrm{FM}$ varied $(r=0.19, P=0.56)$. This indicates good agreement between the two ADP units in estimating $\% \mathrm{FM}$ in small infants.

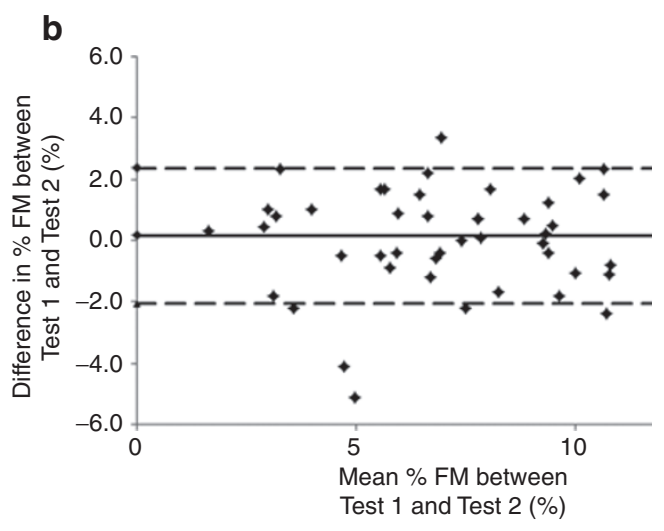

Figure 1. Results of the regression and Bland-Altman analysis. (a) Comparison of ADP Test 1 and Test 2 results for percentage body fat (\%FM). The regression line $\left(R^{2}=0.85 ; \mathrm{SEE}=2.1 \% \mathrm{FM} ; P<0.001\right)$ is not significantly different from the line of identity (dashed line; $y=x$ ). (b) Bland-Altman scatter plot for the two ADP tests. The solid line represents the mean difference (bias $0.15 \% \mathrm{FM})$, and the two dashed lines are the $95 \%$ limits of agreement $( \pm 2$ SD from the mean difference). ADP, air displacement plethysmography; FM, fat mass; $\mathrm{SEE}$, standard error of estimate. 


\section{Articles | Roggero et al.}
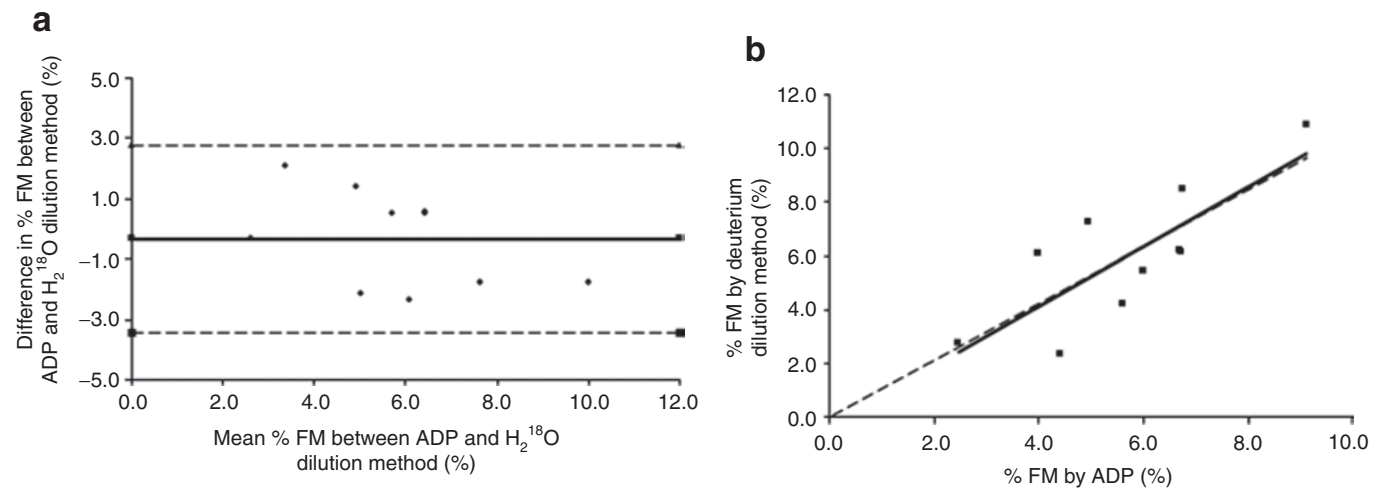

Figure 2. Results of the Bland-Altman and correlation analysis. (a) Bland-Altman scatter plot for the two methods. The solid line represents the mean difference (bias $0.32 \% \mathrm{FM}$ ), and the two dashed lines are the $95 \%$ limits of agreement ( $\pm 2 \mathrm{SD}$ from the mean difference). (b) Relation of $\% \mathrm{FM}$ obtained with the ADP system and the $\mathrm{H}_{2}{ }^{18} \mathrm{O}$ dilution method (reference model) $\left(R^{2}=0.62 ; \mathrm{SEE}=1.65 \% \mathrm{FM} ; P=0.006\right)$. The dashed line represents the line of identity $(y=x)$. ADP, air-displacement plethysmography; FM, fat mass; SEE, standard error of estimate.

Table 3. Individual characteristics of subjects tested (nine full-term and three preterm)

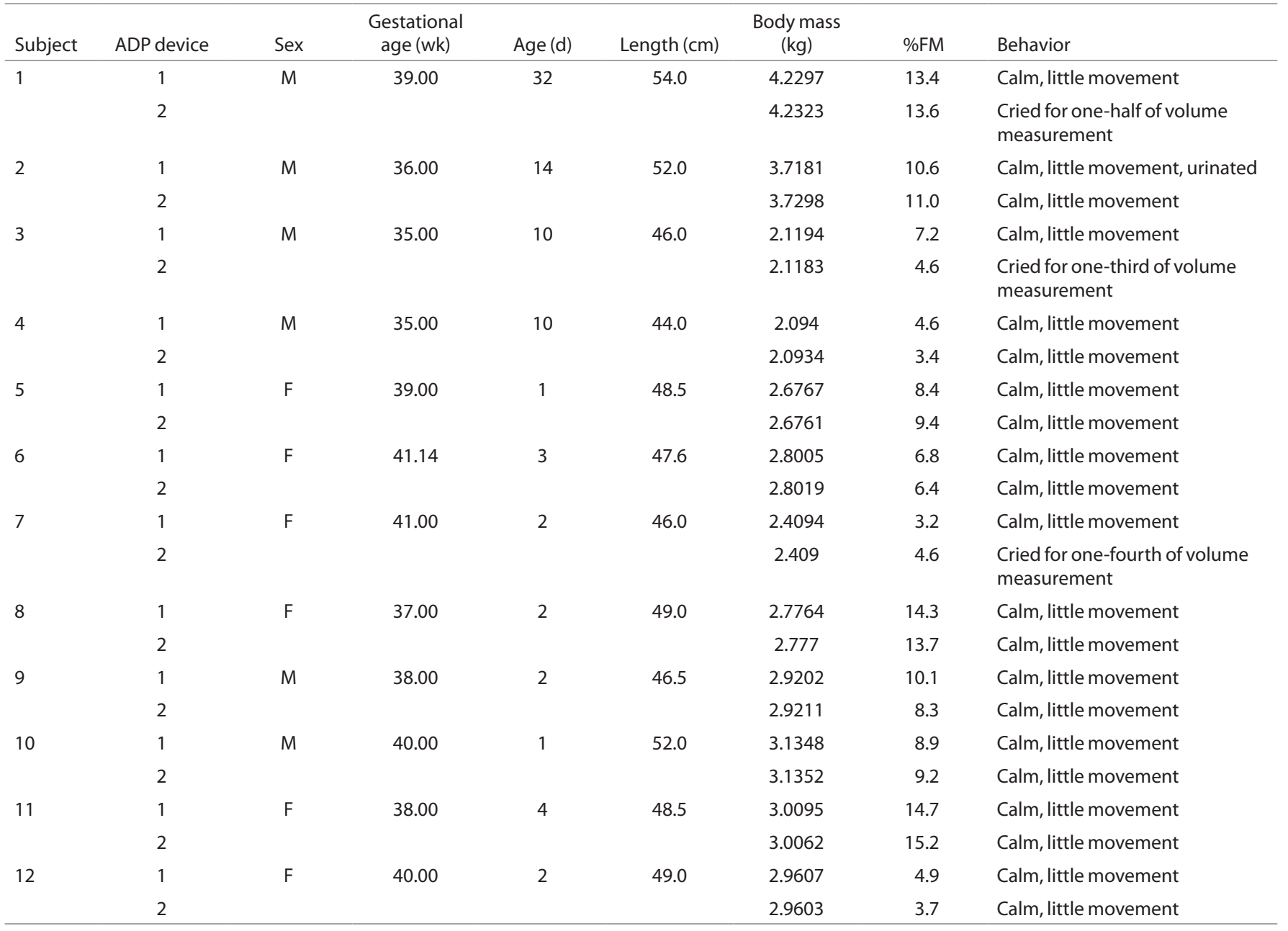

ADP, air-displacement plethysmography; FM, fat mass.

\section{DISCUSSION}

This study is the first to evaluate the ADP system for use in preterm infants for both precision and accuracy of \%FM estimates as compared with that of a reference $\mathrm{H}_{2}{ }^{18} \mathrm{O}$ dilution method. As the aforementioned results indicate, precision of the ADP system was excellent, with a mean difference of $0.15 \%$ between repeated ADP tests. Similarly, there was good agreement between ADP and the $\mathrm{H}_{2}{ }^{18} \mathrm{O}$ dilution method, as indicated by a mean difference of $0.32 \% \mathrm{FM}$ and $95 \%$ limit of agreement at -3.4 and $2.76 \%$ FM. In addition, regression 

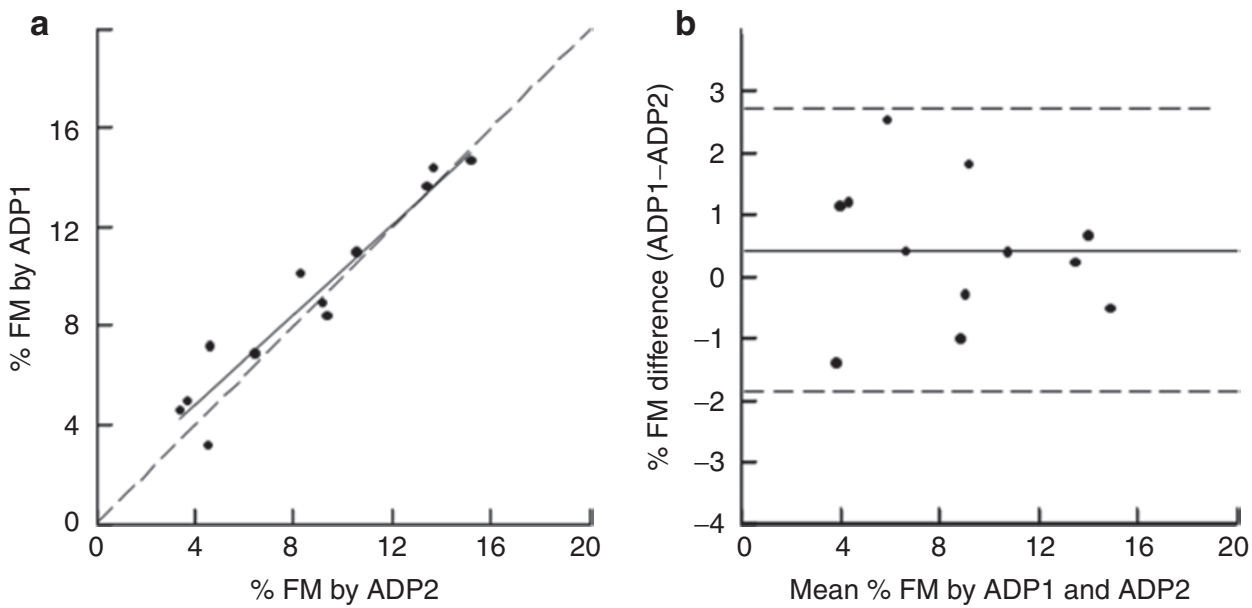

Figure 3. Results of the regression and Bland-Altman analysis. (a) Linear regression of \%FM estimates obtained from ADP Test 1 and ADP Test $2\left(R^{2}=0.9\right.$; $\mathrm{SEE}=1.14 \% \mathrm{FM} ; P<0.001)$. The dashed line represents the line of identity $(y=x)$. (b) Bland-Altman analyses of \%FM estimates obtained from ADP Test 1 and ADP Test 2. ADP, air displacement plethysmography; FM, fat mass; SEE, standard error of estimate.

analyses with the two methods provided a low SEE value of $1.65 \%$ and a moderate $R^{2}$ value of 0.62 . These results show that the ADP system is both precise and accurate in estimating \%FM in preterm infants as compared with the reference $\mathrm{H}_{2}^{18} \mathrm{O}$ dilution technique. In addition, this study assessed the interdevice reliability of the ADP system in human subjects, which was previously evaluated only in inanimate objects. The interdevice reliability data obtained from two pairs of ADP units were excellent.

The results from our study are similar to those obtained in previous ADP validation studies in full-term infants. An ADP validation study conducted with a reference fourcompartment model (11) reported a mean difference of 0.4 $\%$ FM between the two methods and a mean within-subject SD of $0.7 \% \mathrm{FM}$. The $95 \%$ limits of agreement were at -6.8 and $8.1 \% \mathrm{FM}$. In another study where deuterium dilution was used as a reference technique (10), a mean difference of $-0.07 \% \mathrm{FM}$ and mean within-subject SD of $0.69 \% \mathrm{FM}$ was reported, with $95 \%$ limits of agreement reported to be -6.84 and $6.71 \% \mathrm{FM}$. The $\mathrm{H}_{2}{ }^{18} \mathrm{O}$ dilution is considered one of the most accurate and reliable methods for assessing body composition in early infants (14). The technique measures TBW and uses FFM hydration values to calculate FFM and consequently FM. However, the $\mathrm{H}_{2}{ }^{18} \mathrm{O}$ dilution is not without its challenges, especially in the preterm population, as the technique is not practical for daily clinical use when one considers the difficulties involved in dose administration, sample collection and the infrastructure and expertise required for sample analysis.

In contrast, the ADP system has several advantages. It is well tolerated by preterm infants, easy to use and results are instantaneous. The noninvasive nature of the measurement makes it ideal for serial measurements in preterm infants to monitor growth. In addition, the excellent interdevice reliability of the ADP system is crucial for determining overall validity and has practical implications for multicenter studies and intersite testing.
In conclusion, $\mathrm{ADP}$ is a noninvasive, reliable, and accurate technique of measuring body composition in infants in both research and clinical settings.

\section{METHODS}

We conducted the study on 79 preterm $(n=70)$ and full-term $(n=9)$ infants. This was a convenience sample as all the infants enrolled were born in our institution and were in-patients at the time of the study. The study was approved by the Departmental Ethics Committee, Fondazione IRCCS "Ca' Granda" Ospedale Maggiore Policlinico, and written consent was obtained from both parents.

With regard to preterm infants, the inclusion criteria were gestational age $\leq 36$ wk and being born singleton. The full-term infants were healthy and had a gestational age $\geq 37 \mathrm{wk}$. The exclusion criteria for both fulland preterm infants were age $>1$ mo of age, presence of congenital diseases, chromosomal abnormalities, respiratory distress syndrome, or severe brain, metabolic, cardiac, or gastrointestinal diseases.

\section{Precision of ADP}

The precision of the ADP system was assessed in 57 preterm infants. Anthropometric measurements were recorded along with body composition measurements via ADP. The precision of ADP measurements was assessed by conducting two ADP tests consecutively. The precision of the ADP system was then evaluated by comparing the \%FM obtained from the two consecutive measurements, i.e., ADP Test 1 and ADP Test 2.

\section{Accuracy of ADP}

The accuracy of the ADP system was assessed in 10 preterm infants. Anthropometric measurements were made along with body composition measurements via ADP. The accuracy of ADP measurements was assessed by performing a single ADP test followed by a $\mathrm{H}_{2}{ }^{18} \mathrm{O}$ dilution measurement. The accuracy of the ADP system was evaluated by comparing the ADP \%FM with the \%FM calculated from the TBW value determined by the $\mathrm{H}_{2}{ }^{18} \mathrm{O}$ dilution method on the same day.

\section{Interdevice Reliability of ADP Measurements}

Interdevice reliability of the ADP system was evaluated in 12 infants ( 9 full-term and 3 preterm). Duplicate body composition tests were performed in immediate succession on each subject using two ADP units located in the same testing room.

$A D P$. Subject mass was measured on an electronic scale accurate to the nearest $0.1 \mathrm{~g}$. Body composition (FM and FFM) was assessed using an infant ADP system (PEA POD Infant Body Composition System, LMI, Concord, CA). A detailed description of the infant ADP system's physical design, operating principles, and validation 
and measurement procedures is provided elsewhere $(7-11)$. The ADP system assesses FM and FFM by direct measurements of body mass and volume and the application of classic densitometric principles. Infants were measured in the ADP system naked. Each ADP test took about $3 \mathrm{~min}$ to complete. Subject volume was measured in an enclosed chamber by applying gas laws that relate pressure changes to volumes of air in the chamber. Body density was then computed from the measured body mass and volume, and inserted into a standard formula $(15,16)$ for estimating the percentage of total body FM according to a two-compartment model. The intraobserver coefficient of variation for the percentage of FM estimates was $0.3 \%$.

$\mathrm{H}_{2}{ }^{18} \mathrm{O}$ dilution. Upon completion of the ADP measurements, two separate pre-dose urine samples were obtained. Within $10-15 \mathrm{~min}$ of collection of the pre-dose urine samples, $1.0 \mathrm{~g}$ of $10 \% \mathrm{H}_{2}{ }^{18} \mathrm{O} / \mathrm{kg}$ body weight (obtained from the ADP weight scale) was administrated to each fasted infant through a naso-gastric tube. The exact dose given was determined by weighing the dose syringe on an analytical balance before and after dose administration. Five hours after dose administration, two separate post-dose urine samples were collected. The exact time of dose administration and sample collection were recorded. The urine samples were stored in a $-20^{\circ} \mathrm{C}$ freezer before they were shipped on dry ice to the USDA/ARS Children's Nutrition Research Center in Houston, Texas, for ${ }^{18} \mathrm{O} /{ }^{16} \mathrm{O}$ isotope ratio measurements by gas-isotope-ratio mass spectrometry (17).

\section{Statistics}

All statistical analyses were performed by using IBM SPSS Statistics (Windows version 20; IBM, Armonk, NY). Values presented in tables are means \pm SDs. The precision of $\%$ FM for the ADP system was determined by calculating the SDs of the measurements. Linear regression and Bland-Altman analyses (18) were performed to assess agreement between \%FM estimates from repeated ADP tests. A paired-sample $t$-test was used to detect a significant difference between the \% FM values obtained by the ADP system and the $\mathrm{H}_{2}{ }^{18} \mathrm{O}$ dilution measurement. Linear regression analysis for \%FM obtained with the $\mathrm{H}_{2}{ }^{18} \mathrm{O}$ dilution measurement and with the ADP system was used to determine whether the slope and intercept differed significantly from the line of identity $(y=x)$. The coefficient of determination $\left(R^{2}\right)$ and the SEE from the linear regression were further calculated. Bland-Altman analysis was also used to determine the limits of agreement between the two methods as well as potential bias.

The interdevice reliability of \%FM for the ADP system was determined by calculating the mean coefficient of variation for \%FM estimates from the two ADP units. A correlation was performed between the \%FM estimates obtained by the two ADP units. A paired-sample $t$-test was performed to detect potential differences between the \%FM values obtained by the two ADP units. Linear regression and BlandAltman analyses were carried out to assess the agreement between the $\% \mathrm{FM}$ estimates assessed by the two ADP units.

\section{STATEMENT OF FINANCIAL SUPPORT}

No financial assistance was received to support this study.

\section{REFERENCES}

1. Ramel SE, Gray HL, Ode KL, Younge N, Georgieff MK, Demerath EW. Body composition changes in preterm infants following hospital discharge: comparison with term infants. J Pediatr Gastroenterol Nutr 2011;53:333-8.

2. Roggero $\mathrm{P}$, Giannì ML, Liotto N, et al. Rapid recovery of fat mass in small for gestational age preterm infants after term. PLoS ONE 2011;6:e14489.

3. Rubin LP. Postnatal growth in preterm infants: too small, too big, or just right? J Pediatr 2009;154:473-5.

4. Lucas A, Fewtrell MS, Cole TJ. Fetal origins of adult disease-the hypothesis revisited. BMJ 1999;319:245-9.

5. Godang K, Qvigstad E, Voldner N, et al. Assessing body composition in healthy newborn infants: reliability of dual-energy x-ray absorptiometry. J Clin Densitom 2010;13:151-60.

6. Wells JC, Fewtrell MS. Measuring body composition. Arch Dis Child 2006;91:612-7.

7. Urlando A, Dempster P, Aitkens S. A new air displacement plethysmograph for the measurement of body composition in infants. Pediatr Res 2003;53:486-92.

8. Sainz RD, Urlando A. Evaluation of a new pediatric air-displacement plethysmograph for body-composition assessment by means of chemical analysis of bovine tissue phantoms. Am J Clin Nutr 2003;77:364-70.

9. Yao M, Nommsen-Rivers L, Dewey K, Urlando A. Preliminary evaluation of a new pediatric air displacement plethysmograph for body composition assessment in infants. Acta Diabetol 2003;40:Suppl 1:S55-8.

10. Ma G, Yao M, Liu Y, et al. Validation of a new pediatric air-displacement plethysmograph for assessing body composition in infants. Am J Clin Nutr 2004;79:653-60.

11. Ellis KJ, Yao M, Shypailo RJ, Urlando A, Wong WW, Heird WC. Bodycomposition assessment in infancy: air-displacement plethysmography compared with a reference 4-compartment model. Am J Clin Nutr 2007;85:90-5.

12. Giannì ML, Roggero P, Taroni F, Liotto N, Piemontese P, Mosca F. Adiposity in small for gestational age preterm infants assessed at term equivalent age. Arch Dis Child Fetal Neonatal Ed 2009;94:F368-72.

13. Roggero $\mathrm{P}$, Giannì ML, Amato $\mathrm{O}$, et al. Is term newborn body composition being achieved postnatally in preterm infants? Early Hum Dev 2009;85:349-52.

14. Lapillonne A, Salle BL. Methods for measuring body composition in newborns-a comparative analysis. J Pediatr Endocrinol Metab 1999;12:125-37.

15. Butte NF, Hopkinson JM, Wong WW, Smith EO, Ellis KJ. Body composition during the first 2 years of life: an updated reference. Pediatr Res 2000;47:578-85.

16. Fomon SJ, Haschke F, Ziegler EE, Nelson SE. Body composition of reference children from birth to age 10 years. Am J Clin Nutr 1982;35:Suppl 5:1169-75.

17. Wong WW, Lee LS, Klein PD. Deuterium and oxygen-18 measurements on microliter samples of urine, plasma, saliva, and human milk. Am J Clin Nutr 1987;45:905-13.

18. Bland JM, Altman DG. Statistical methods for assessing agreement between methods of clinical measurement. Lancet 1986;1:301-10. 